\title{
Lung and thorax development during adolescence: relationship with pubertal status
}

\author{
V. Nève*, F. Girard" ${ }^{\#}$ A. Flahault ${ }^{\mp}$, M. Boulé*
}

Lung and thorax development during adolescence: relationship with pubertal status. V. Nève, F. Girard, A. Flahault, M. Boulé. (C) ERS Journals Ltd 2002.

ABSTRACT: The aim of the present study was to define reference values for lung volumes and the lung transfer factor for carbon monoxide $(T \mathrm{~L}, \mathrm{CO})$ for an adolescent population using thoracic volume index (TVI) and an index of pubertal stage in order to account for the variation in growth pattern between adolescents.

TVI, pubertal stage by Tanner scale (PST), time since menarche, functional residual capacity measured using the helium-dilution technique, vital capacity, total lung capacity and $T_{\mathrm{L}}, \mathrm{CO}$ measured using a steady-state method were determined in 51 males (aged 13-20 yrs; PST T3-T5) and 52 females (aged 13-18 yrs; PST T2-T4; all but three had already undergone menarche).

In male adolescents, height, weight, TVI, lung volumes and TL,CO increased with age. This was not the case in female adolescents. In males, the TVI was the independent variable that best correlated with pulmonary volumes. In females, height was the independent variable that best correlated with pulmonary volumes. In both sexes, the variable that best correlated with $T \mathrm{~L}, \mathrm{CO}$ was PST, associated with height in males.

This cross-sectional study provides prediction equations for lung volumes and the lung transfer factor for carbon monoxide taking into account thoracic volume index and pubertal stage. It shows that, in adolescent males, lung and thoracic development occurs during and until the end of puberty. Conversely, in adolescent females, lung development is almost finished following menarche.

Eur Respir J 2002; 20: 1292-1298.

\begin{abstract}
*Laboratory of Respiratory Physiology, and ${ }^{\#}$ Laboratory of Endocrinology, Hôpital d'Enfants Armand Trousseau, and "Dept of Biostatistics, Hôpital Tenon, Paris, France.
\end{abstract}

Correspondence: M. Boulé

Laboratoire de Physiologie Respiratoire Hôpital d'Enfants Armand Trousseau Avenue du Dr Arnold Netter, 26 75012 Paris

France

Fax: 33144736336

E-mail: michele.boule@trs.ap-hopparis.fr

\section{Keywords: Adolescence diffusing capacity lung growth reference values thoracic volume index}

Received: January 292001 Accepted after revision: June 92002
Many studies have described the increase in forced expiratory flows occurring during adolescence but little is known about the increase in thoracic measurements, lung volumes and lung transfer factor for carbon monoxide $(T \mathrm{~L}, \mathrm{CO})$.

It is known that lung function increases linearly with age and height until the adolescent growth spurt at $\sim 10$ yrs in females and $\sim 12$ yrs in males $[1,2]$. At adolescence, lung function no longer increases proportionally to height but rather follows a more complex pattern. Initially, trunk length lags behind leg length temporally; then the lung grows in diameter followed by length [3]; and, finally, lung volumes continue to increase after adult height has been reached due to prolonged increase in muscle strength [4-6]. Therefore, lung function increases proportionally to trunk and chest dimension rather than to height [7]. In addition, the timing of the events of puberty differs dependent on sex, and individual development may deviate considerably from that suggested by the average growth profile [8].

The sudden change in spirometric lung function seen in males and females appears to coincide with the pubertal growth spurt observed in the Tanner chart [9]. To account for the variation in growth pattern between adolescents in reference equations, in addition to height, a measure of pubertal status and an estimation of thoracic volume should be incorporated. This would allow for the fact that the growth of the lungs lag behind that of the legs and height $[8,10,11]$.

Extrapolation of reference values from children to an adolescent population cannot be used to predict lung volumes and $T \mathrm{~L}, \mathrm{CO}$. Therefore, summary equations and limits of normal values need to be determined for use in current clinical practice.

Therefore, the aim of the present study was to derive prediction equations for lung volumes and $T \mathrm{~L}, \mathrm{CO}$ for adolescent males and females using refined anthropometric measurements allowing determination of thoracic growth (such as thoracic volume index (TVI)) and an index of growth stage (pubertal stage).

\section{Subjects and methods}

\section{Subjects}

Having obtained the authorisation of the Department of Education (Versaille, France) to ask all pupils attending two levels of a secondary school (fourth and sixth year) in Paris, France, to participate in the study, 103 pupils (51 males and 52 females) gave their oral consent and were included. Written parental consent was also obtained. 
Lung examination and spirometric results were normal on the day of the pulmonary function tests.

\section{Methods}

Anthropometric data. Height was determined to the nearest $5 \mathrm{~mm}$ and weight to the nearest $500 \mathrm{~g}$. In order to determine TVI $(\mathrm{mL})$, the anteroposterior diameter at the sternal angle (AP2), biacromial diameter (BA), sternal length (SL), anteroposterior diameter at the xiphisternal junction (APx) and transthoracic diameter (TT) were measured during the resting end-tidal phase of respiration using a pelvimetry calliper. The TVI was calculated using the following formula: $\mathrm{AP} 2 \times \mathrm{TT} \times \mathrm{SL}$ [10].

Pubertal status. Pubertal status, based on the fivepoint rating scale (T1-T5) of TANNER [9], was assessed for males and females by an endocrinologist. The qualitative Tanner score was converted into a quantitative variable (pubertal stage by Tanner scale (PST)): T1: 0; T2: 0; T3: 1; T4: 2; and T5: 3 . In addition, in females, the time since menarche was evaluated and categorised as follows: 0: menarche had not yet occurred; 1: $<2$ yrs since menarche; 2: 2-4 yrs since menarche; and 3: $>4$ yrs since menarche.

Pulmonary function tests. Spirometric measurements included vital capacity (VC), functional residual capacity (FRC), measured using the helium dilution technique, residual volume (RV), obtained by subtracting expiratory reserve from FRC, and total lung capacity (TLC), calculated from VC plus RV. TL,CO was measured using a steady-state method [12]. The same person made all the measurements according to the recommendations of the European Respiratory Society [13] with the subject seated in an upright posture and wearing a nose clip.

Statistical analysis. Pulmonary function test results and anthropometric data were analysed separately for males and females. The means of the anthropometric data from males and females were compared by unpaired t-test. The Pearson correlation coefficient $\left(\mathrm{r}_{\mathrm{P}}\right)$ was used to compare pulmonary function test and anthropometric data. A p-value of $<0.05$ was considered significant [14].

In order to determine whether or not logarithmic transformation was required, the variance of the pulmonary function data was determined [15]: males and females were divided into groups on the basis of $3-\mathrm{cm}$ height intervals. The mean and SD of the pulmonary function test results for each group were plotted against each other. Correlation was evaluated using the Spearman correlation coefficient $\left(\mathrm{r}_{\mathrm{S}}\right)$ as only 10 height groups were obtained [14]. When SD did not increase with mean $\left(r_{s}>0.05\right)$, constant variance was assumed and no transformation was performed before multiple regression. When SD increased with mean, increased scatter with height was assumed and logarithmic transformation of the data was performed. After having checked that this transformation had stabilised the variance, multiple regression of the log-transformed pulmonary function test data was performed.

Multiple regression of pulmonary function parameters or log-transformed pulmonary function parameters on anthropometric data was then performed. Height was chosen in the first step [16], except in the female group when $T \mathrm{~L}, \mathrm{CO}$ was the dependent variable as no correlation between height and TL,CO was found. Other independent variables were included by decreasing partial $r_{P}$ until no further increase in $R^{2}$ adjusted for the increase in the number of independent variables included in the equation $\left(\mathrm{R}_{a}^{2}\right)$ was obtained [14].

\section{Results}

\section{Anthropometric data}

Mean male age (16 yrs, range 13-20 yrs) was not significantly different from mean female age $(16 \mathrm{yrs}$, range $13-18 \mathrm{yrs}, \mathrm{p}=0.22)$. Males were taller $(172 \mathrm{~cm}$, range $150-184 \mathrm{~cm}$ versus $163 \mathrm{~cm}$, range $147-176 \mathrm{~cm}$, $\mathrm{p}<0.0001)$ and heavier $(61 \mathrm{~kg}$, range $42-84 \mathrm{~kg}$ versus $53 \mathrm{~kg}$, range $39-68 \mathrm{~kg}, \mathrm{p}<0.0001)$ than females.

In males, height and weight increased with age $\left(\mathrm{r}_{\mathrm{P}}=0.45, \mathrm{p}<0.01\right.$ and $\mathrm{r}_{\mathrm{P}}=0.42, \mathrm{p}<0.01$, respectively); the height increase reached a plateau at 16-17 yrs.

Conversely, in females, neither height nor weight increased with age $\left(r_{p}=0.025\right.$, NS and $r_{P}=0.05$, NS, respectively).

Thoracic measurements (mean $\pm \mathrm{SD}$ and range) in males and females are reported in table 1 . The mean thoracic measurements of males were greater than those of females, except SL, which was significantly longer in females.

The correlation of thoracic measurements with anthropometric data is reported in table 2. In males, TVI, BA and AP2 increased with age and continued to increase when height had reached a plateau. APx and SL did not increase with age. In females, neither TVI nor thoracic measurement increased with age.

\section{Pubertal status}

No males were prepubescent (T1), 11 were in early puberty (all T3) and most in late puberty (15 in T4 and 24 in T5). No females were prepubescent, most were in early puberty (two in T2 and 20 in T3) and nine in late puberty (all T4). These Tanner scores were converted into PST as described in the Methods section. Nine of the females were in menarcheal category 1,14 in category 2 and 12 in category 3 .

\section{Pulmonary function tests}

Partial Pearson correlation coefficients $\left(\mathrm{r}_{\mathrm{P}}\right)$ between pulmonary function test parameters and anthropometric data are reported in tables 3 and 4 . In females, height $(\mathrm{H})$ was the independent variable that best correlated with pulmonary volumes: TLC $=0.08 \mathrm{H}$ 7.78, $\mathrm{r}_{\mathrm{p}}=0.69, \quad \mathrm{R}^{2}=0.48, \mathrm{p}=3 \times 10^{-7} ; \quad \mathrm{VC}=0.06 \mathrm{H}-5.41$, 
Table 1. - Thoracic measurements in adolescent males and females

\begin{tabular}{lccc}
\hline & Males & Females & p-value $^{\#}$ \\
\hline Subjects n & 40 & 34 & \\
AP2 cm & $13.6 \pm 1.1(11-16.5)$ & $12.5 \pm 1.4(10-17)$ & 0.00001 \\
APx cm & $18.0 \pm 1.5(15-21)$ & $16.9 \pm 1.5(14.5-21)$ & 0.0004 \\
BA cm & $37.4 \pm 2.2(33-43)$ & $36.1 \pm 2.0(32-41)$ & 0.002 \\
SL cm & $16.6 \pm 1.8(13-22)$ & $17.4 \pm 1.3(14-20)$ & 0.008 \\
TT cm & $26.5 \pm 1.7(24-30)$ & $25.1 \pm 1.5(21-28)$ & 0.00004 \\
TVI mL & $5956 \pm 1010(4320-8910)$ & $5478 \pm 955(3465-7514)$ & 0.002 \\
\hline
\end{tabular}

Data are presented as mean \pm SD (range). AP2: anteroposterior diameter at the sternal angle; APx: anteroposterior diameter at the xiphisternal junction; BA: biacromial diameter; SL: sternal length; TT: transthoracic diameter; TVI: thoracic volume index. ${ }^{\#}$ : unpaired t-test (a p-value of $<0.05$ was considered significant).

Table 2. - Partial Pearson correlation coefficients for thoracic measurements and anthropometric data in adolescent males and females

\begin{tabular}{|c|c|c|c|c|c|c|}
\hline & BA & $\mathrm{TT}$ & AP2 & APx & SL & TVI \\
\hline \multicolumn{7}{|l|}{ Females } \\
\hline Age & -0.24 & 0.03 & -0.04 & -0.09 & -0.21 & -0.04 \\
\hline Height & $0.35^{\#}$ & $0.32 *$ & $0.61 * * *$ & $0.64 * * *$ & $0.36^{\#}$ & $0.54^{* * *}$ \\
\hline Weight & 0.04 & 0.21 & $0.47 * * *$ & 0.25 & $0.51 * * *$ & $0.67 * * *$ \\
\hline PST & -0.18 & $0.35^{*}$ & $0.32 *$ & 0.14 & 0.004 & 0.27 \\
\hline \multicolumn{7}{|l|}{ Males } \\
\hline Age & $0.62 * * *$ & $0.43^{* * *}$ & $0.37^{\#}$ & 0.14 & 0.19 & $0.45^{* * *}$ \\
\hline Height & $0.30^{*}$ & $0.53 * * *$ & 0.28 & 0.20 & $0.34^{*}$ & $0.68 * * *$ \\
\hline Weight & $0.57 * * *$ & $0.69 * * *$ & $0.42 * * *$ & $0.63 * * *$ & 0.26 & $0.58 * * *$ \\
\hline PST & $0.44 * * *$ & $0.47 * * *$ & $0.32 *$ & 0.16 & 0.06 & $0.30^{*}$ \\
\hline
\end{tabular}

BA: biacromial diameter; TT: transthoracic diameter at the level of the xiphisternal junction; AP2: anteroposterior diameter at the level of the manubriosternal junction (sternal angle); APx: anteroposterior diameter at the level of the xiphisternal junction; SL: sternal length; TVI: thoracic volume index; PST: pubertal stage by Tanner scale. ${ }^{*}: \mathrm{p}<0.05$; ${ }^{\#}: \mathrm{p}<0.02$; $* * *: \mathrm{p}<0.001$.

$\mathrm{r}_{\mathrm{p}}=0.71, \mathrm{R}^{2}=0.50, \mathrm{p}=1 \times 10^{-7} ;$ and $\mathrm{FRC}=0.04 \mathrm{H}-5, \mathrm{r}_{\mathrm{p}}=$ $0.57, \mathrm{R}^{2}=0.32, \mathrm{p}=4 \times 10^{-5}$.

In males, TVI was the independent variable that best correlated with pulmonary volumes: TLC $=$ $0.0006 \mathrm{TVI}+1.2, \quad \mathrm{r}_{\mathrm{p}}=0.77, \quad \mathrm{R}^{2}=0.59, \quad \mathrm{p}=1 \times 10^{-7} ; \quad \mathrm{VC}=$ 0.0006 TVI+1.16, $\quad \mathrm{r}_{\mathrm{p}}=0.75, \quad \mathrm{R}^{2}=0.56, \quad \mathrm{p}=2 \times 10^{-7} ; \quad$ and $\mathrm{FRC}=0.0004 \mathrm{TVI}+0.36, \mathrm{r}_{\mathrm{p}}=0.66, \mathrm{R}^{2}=0.44, \mathrm{p}=2 \times 10^{-5}$.

In both sexes, the variable that best correlated with $T \mathrm{~L}, \mathrm{CO}$ was PST, associated to height in males. In females, $T \mathrm{~L}, \mathrm{CO}=3.643 \mathrm{PST}+11.587, \mathrm{r}_{\mathrm{p}}=0.50, \mathrm{R}^{2}=0.25$, $\mathrm{p}=0.015$. In males, $T \mathrm{~L}, \mathrm{CO}=4.59 \mathrm{PST}+14.96, \mathrm{r}_{\mathrm{p}}=0.61$, $\mathrm{R}^{2}=0.37, \mathrm{p}=3 \times 10^{-5}$; and $T \mathrm{~L}, \mathrm{CO}=0.45 \mathrm{H}-52.68, \mathrm{r}_{\mathrm{p}}=0.58$, $\mathrm{R}^{2}=0.34, \mathrm{p}=1 \times 10^{-4}$.

\section{Variance of pulmonary function test data}

In males, the SD of FRC, VC and TLC within a $3-\mathrm{cm}$ height group did not increase with mean $\left(r_{S}=-0.018,0.57\right.$ and 0.24 , respectively, all $\left.p>0.05\right)$. In females, the SD of $T \mathrm{~L}, \mathrm{CO}, \mathrm{VC}$ and TLC within a $3-\mathrm{cm}$ height group did not increase with mean $\left(r_{S}=-0.066\right.$, $\mathrm{p}>0.05$ for TL,CO; $\mathrm{r}_{\mathrm{S}}=0.40, \mathrm{p}>0.05$ for $\mathrm{VC}$; and $\mathrm{r}_{\mathrm{S}}=0.62, \mathrm{p}>0.05$ for TLC). Therefore constant variance could be assumed and FRC, VC and TLC in males and TL,CO, VC and TLC in females were regressed with anthropometric data.

Conversely, in males, the SD of $T \mathrm{~L}, \mathrm{CO}$ within a $3-\mathrm{cm}$ height group increased with mean $\left(\mathrm{r}_{\mathrm{S}}=0.72\right.$, $\mathrm{p}<0.05)$ and the intercept did not differ from zero $(p=0.28)$. Natural log transformation stabilised variance $\left(\mathrm{r}_{\mathrm{S}}=0.224, \mathrm{p}>0.05\right)$. In females, the SD of FRC within a $3-\mathrm{cm}$ height group increased with mean $\left(r_{S}=0.81, p<0.05\right)$ and could be assumed to be proportional to the mean as the intercept of the regression line did not differ significantly from zero $(\mathrm{p}=0.06)$. Natural $\log$ transformation stabilised variance $\left(r_{S}=0.51, p>0.05\right)$. For FRC in females and $T \mathrm{~L}, \mathrm{CO}$ in males, a similar $\mathrm{R}^{2}$ was obtained by fitting by a power or exponential function to the data. Therefore, it was decided to perform simple log transformation and regress natural log-transformed $T \mathrm{~L}, \mathrm{CO}$ on height in males and natural $\log$ FRC on height in females.

\section{Multiple regression equation}

The rank order in which independent variables were included in the equation and their contribution to the explained variance $\left(\mathrm{R}_{a}^{2}\right)$ are listed in tables 5 and 6 . In males, height and then TVI were included in the multiple regression equation for lung volumes (FRC, TLC and VC). PST was also included in the multiple regression equation for VC and TLC. Height and then PST were included in the regression equation for $T \mathrm{~L}, \mathrm{CO}$. In females, height and then time since menarche were included in the multiple regression equation for FRC, and height and then TVI in the regression equation for TLC and VC. PST was the 
Table 3. - Partial Pearson correlation coefficients $\left(r_{\mathrm{P}}\right)$ and regression equations for pulmonary function parameters with anthropometric data in adolescent females

\begin{tabular}{|c|c|c|c|c|c|}
\hline & Subjects $\mathrm{n}$ & $r_{P}$ & Regression & $\mathrm{R}^{2}$ & $\mathrm{p}$-value \\
\hline \multicolumn{6}{|l|}{ TLC } \\
\hline Height & 43 & 0.69 & $0.08 x-7.78$ & 0.48 & $3 \times 10^{-7}$ \\
\hline TVI & 34 & 0.49 & $0.0004 x+2.48$ & 0.24 & $3 \times 10^{-3}$ \\
\hline Weight & 43 & 0.44 & $0.05 x+1.97$ & 0.19 & $3 \times 10^{-3}$ \\
\hline $\mathrm{PS} t$ & 31 & 0.33 & $0.159 x+4.0549$ & 0.11 & 0.07 \\
\hline PScateg & 31 & 0.30 & $4.534 \pm 0.73$ & 0.09 & 0.10 \\
\hline PST & 27 & 0.33 & $4.534 \pm 0.73$ & 0.11 & 0.10 \\
\hline Age & 43 & 0.18 & $4.534 \pm 0.73$ & 0.03 & 0.26 \\
\hline \multicolumn{6}{|l|}{$\mathrm{VC}$} \\
\hline Height & 43 & 0.71 & $0.06 x-5.41$ & 0.50 & $1 \times 10^{-7}$ \\
\hline TVI & 34 & 0.59 & $0.0003 x+1.9$ & 0.35 & $2 \times 10^{-4}$ \\
\hline Weight & 43 & 0.57 & $0.04 x+1.28$ & 0.32 & $1 \times 10^{-4}$ \\
\hline PST & 27 & 0.32 & $3.5 \pm 0.512$ & 0.10 & 0.11 \\
\hline $\mathrm{PS} t$ & 31 & 0.24 & $3.5 \pm 0.512$ & 0.06 & 0.10 \\
\hline PScateg & 31 & 0.23 & $3.5 \pm 0.512$ & 0.05 & 0.22 \\
\hline Age & 43 & 0.04 & $3.5 \pm 0.512$ & 0.002 & 0.82 \\
\hline \multicolumn{6}{|l|}{ FRC } \\
\hline Height & 46 & 0.57 & $0.04 x-5$ & 0.32 & $4 \times 10^{-5}$ \\
\hline $\mathrm{PS} t$ & 32 & 0.32 & $0.1106 x+1.815$ & 0.10 & 0.07 \\
\hline PScateg & 32 & 0.28 & $0.1919 x+1.7798$ & 0.08 & 0.12 \\
\hline Age & 46 & 0.25 & $2.13 \pm 0.53$ & 0.06 & 0.23 \\
\hline TVI & 35 & 0.21 & $2.13 \pm 0.53$ & 0.04 & 0.23 \\
\hline Weight & 46 & 0.19 & $2.13 \pm 0.53$ & 0.04 & 0.21 \\
\hline PST & 27 & 0.16 & $2.13 \pm 0.53$ & 0.03 & 0.42 \\
\hline \multicolumn{6}{|l|}{$T \mathrm{~L}, \mathrm{CO}$} \\
\hline PST & 23 & 0.50 & $3.643 x+11.587$ & 0.25 & 0.015 \\
\hline PScateg & 30 & 0.28 & $9.58 \pm 2.73$ & 0.08 & 0.13 \\
\hline $\mathrm{PS} t$ & 30 & 0.20 & $9.58 \pm 2.73$ & 0.04 & 0.30 \\
\hline Weight & 43 & 0.19 & $9.58 \pm 2.73$ & 0.04 & 0.22 \\
\hline Age & 43 & 0.17 & $9.58 \pm 2.73$ & 0.03 & 0.28 \\
\hline TVI & 31 & -0.10 & $9.58 \pm 2.73$ & 0.01 & 0.59 \\
\hline Height & 43 & 0.07 & $9.58 \pm 2.73$ & 0.01 & 0.64 \\
\hline \multicolumn{6}{|l|}{ TVI } \\
\hline Weight & 31 & 0.48 & $92 x+649$ & 0.23 & 0.007 \\
\hline Height & 39 & 0.55 & 77.33-7075 & 0.30 & $3 \times 10^{-4}$ \\
\hline Age & 39 & -0.04 & $5478 \pm 976$ & 0.002 & 0.44 \\
\hline \multicolumn{6}{|l|}{ RV/TLC } \\
\hline Age & 44 & 0.44 & $0.017 x-0.0645$ & 0.19 & $4 \times 10^{-3}$ \\
\hline \multicolumn{6}{|l|}{$T \mathrm{~L}, \mathrm{CO} / \mathrm{FRC}$} \\
\hline Age & 36 & -0.15 & $9.58 \pm 2.73$ & 0.02 & 0.38 \\
\hline
\end{tabular}

When $\mathrm{r}_{\mathrm{P}}$ is nonsignificant, mean $\pm \mathrm{SD}$ is given. TLC: total lung capacity (L); VC: vital capacity (L); FRC: functional residual capacity $(\mathrm{L})$; TL,CO: lung transfer factor for carbon monoxide $\left(\mathrm{mL} \cdot \mathrm{min}^{-1} \cdot \mathrm{mmHg}^{-1}\right)$; TVI: thoracic volume index $(\mathrm{mL})$; RV: residual volume (L); PST: pubertal stage by Tanner scale; PSt: pubertal stage by time since menarche (yrs); PScateg: pubertal stage by menarcheal category.

only independent variable included in the regression equation for $T \mathrm{~L}, \mathrm{CO}$ as it was the only one that correlated to $T \mathrm{~L}, \mathrm{CO}$, with height in males. As a general rule, $\mathrm{R}_{a}^{2}$ were higher in males than in females.

Limits of normal. The mean and SD of the residuals (differences between actual and predicted value) for each adolescent are presented in tables 5 and 6 . They are expressed as a ratio of lung function to predicted lung function. They range $9-17 \%$ pred in males and $10-17 \%$ pred in females.

\section{Discussion}

The present study provides reference values for TVI, lung volumes and TL,CO for adolescent males and females. No other reports on normal values of TVI and thoracic measurements in an adolescent population could be located. Besides its importance in providing normal values for thoracic mensurations in adolescents for height and age, these reference values could be of help in quantifying the chest wall sequelae of treatments, such as radiotherapy, and the decrease in chest wall volume due to decrease in muscle strength in neuromuscular disease. In addition, this study has the advantage of providing reference values for lung volumes and $T \mathrm{~L}, \mathrm{CO}$ using equations that take height as well as TVI and pubertal stage into consideration, an approach allowing variation in growth pattern between adolescents to be taken into account $[8,11]$.

Data were obtained from a group of males aged 13-20 yrs whose PST ranged T3-T5 and a group of 
Table 4. - Partial Pearson correlation coefficients $\left(r_{\mathrm{P}}\right)$ and regression equations for pulmonary function parameters with anthropometric data in adolescent males

\begin{tabular}{|c|c|c|c|c|c|}
\hline & Subjects $\mathrm{n}$ & $r_{P}$ & Regression & $\mathrm{R}^{2}$ & p-value \\
\hline \multicolumn{6}{|l|}{ TLC } \\
\hline TVI & 38 & 0.77 & $0.0006 x+1.2$ & 0.59 & $1 \times 10^{-7}$ \\
\hline Height & 38 & 0.70 & $0.12 x-14.39$ & 0.49 & $1 \times 10^{-6}$ \\
\hline PST & 38 & 0.65 & $0.89 x+3.68$ & 0.42 & $1 \times 10^{-5}$ \\
\hline Age & 38 & 0.59 & $0.41 x-0.77$ & 0.35 & $1 \times 10^{-4}$ \\
\hline Weight & 38 & 0.57 & $0.07 x+1.63$ & 0.32 & $2 \times 10^{-4}$ \\
\hline \multicolumn{6}{|l|}{$\mathrm{VC}$} \\
\hline TVI & 34 & 0.75 & $0.0006 x+1.16$ & 0.56 & $2 \times 10^{-7}$ \\
\hline Height & 40 & 0.65 & $0.08 x-9.92$ & 0.42 & $1 \times 10^{-5}$ \\
\hline PST & 39 & 0.63 & $0.65 x+3.05$ & 0.40 & $1 \times 10^{-5}$ \\
\hline Weight & 40 & 0.60 & $0.06 x+1.2$ & 0.36 & $5 \times 10^{-5}$ \\
\hline Age & 40 & 0.59 & $0.31 x-0.31$ & 0.35 & $1 \times 10^{-4}$ \\
\hline \multicolumn{6}{|l|}{ FRC } \\
\hline TVI & 34 & 0.66 & $0.0004 x+0.36$ & 0.44 & $2 \times 10^{-5}$ \\
\hline Height & 45 & 0.63 & $0.05 x-5.49$ & 0.40 & $6 \times 10^{-4}$ \\
\hline Age & 45 & 0.54 & $0.19 x-0.53$ & 0.29 & $2 \times 10^{-4}$ \\
\hline Weight & 45 & 0.48 & $0.03 x+0.75$ & 0.23 & $1 \times 10^{-3}$ \\
\hline PST & 45 & 0.48 & $0.35 x+1.76$ & 0.23 & $1 \times 10^{-3}$ \\
\hline \multicolumn{6}{|l|}{$T \mathrm{~L}, \mathrm{CO}$} \\
\hline PST & 40 & 0.61 & $4.59 x+14.96$ & 0.37 & $3 \times 10^{-5}$ \\
\hline Height & 40 & 0.58 & $0.45 x-52.68$ & 0.34 & $1 \times 10^{-4}$ \\
\hline Age & 40 & 0.50 & $2.37 x-12.48$ & 0.25 & $1 \times 10^{-3}$ \\
\hline Weight & 40 & 0.49 & $0.34 x+4.36$ & 0.24 & $1 \times 10^{-3}$ \\
\hline TVI & 25 & 0.37 & $0.0023 x+12.91$ & 0.14 & 0.04 \\
\hline \multicolumn{6}{|c|}{ (1) } \\
\hline Height & 40 & 0.68 & $110 x-13143$ & 0.46 & $2 \times 10^{-6}$ \\
\hline Weight & 40 & 0.58 & $72 x+1382$ & 0.34 & $1 \times 10^{-4}$ \\
\hline Age & 40 & 0.45 & $326 x+648$ & 0.20 & $3 \times 10^{-3}$ \\
\hline \multicolumn{6}{|l|}{ RV/TLC } \\
\hline Age & 38 & 0.07 & $0.20 \pm 0.04$ & 0.01 & 0.69 \\
\hline \multicolumn{6}{|l|}{$T \mathrm{~L}, \mathrm{CO} / \mathrm{FRC}$} \\
\hline Age & 35 & 0.07 & $10.02 \pm 2.29$ & 0.01 & 0.69 \\
\hline
\end{tabular}

When $r_{P}$ is nonsignificant, mean $\pm S D$ is given. TLC: total lung capacity (L); VC: vital capacity (L); FRC: functional residual capacity $(\mathrm{L})$; TL,CO: lung transfer factor for carbon monoxide $\left(\mathrm{mL} \cdot \mathrm{min}^{-1} \cdot \mathrm{mmHg}^{-1}\right)$; TVI: thoracic volume index $(\mathrm{mL})$; RV: residual volume (L); PST: pubertal stage by Tanner scale.

Table 5. - Multiple regression equations for adolescent males

\begin{tabular}{lccrr}
\hline Dependent variable & Equation & Adjusted R $^{2}$ & Residual $^{\#}$ & p-value \\
\hline FRC & $-5.4873+0.0470 \mathrm{H}$ & 0.39 & $1.00 \pm 0.18$ & $1 \times 10^{-6}$ \\
& $-4.1759+0.0305 \mathrm{H}+0.2535 \mathrm{TVI}$ & 0.47 & $1.00 \pm 0.16$ & $1 \times 10^{-5}$ \\
TLC & $-14.445+0.1172 \mathrm{H}$ & 0.47 & $1.01 \pm 0.12$ & $1 \times 10^{-6}$ \\
& $-8.3176+0.0636 \mathrm{H}+0.5221 \mathrm{TVI}$ & 0.64 & $1.00 \pm 0.11$ & $1 \times 10^{-7}$ \\
VC & $-6.1656+0.04699 \mathrm{H}+0.4232 \mathrm{TVI}+0.5459 \mathrm{PST}$ & 0.72 & $1.00 \pm 0.09$ & $1 \times 10^{-8}$ \\
& $-5.8434+0.0468 \mathrm{H}+0.3967 \mathrm{TVI}$ & 0.41 & $1.00 \pm 0.13$ & $1 \times 10^{-5}$ \\
& $-3.9629+0.0329 \mathrm{H}+0.3164 \mathrm{TVI}+0.4106 \mathrm{PST}$ & 0.61 & $1.00 \pm 0.11$ & $1 \times 10^{-7}$ \\
TL,CO & $0.8378 \mathrm{e}^{0.0197 \mathrm{H}}$ & 0.69 & $1.00 \pm 0.09$ & $1 \times 10^{-8}$ \\
& $1.686 \mathrm{e}^{0.0141 \mathrm{H}} \mathrm{e}^{0.1196 \mathrm{PST}}$ & 0.37 & $1.02 \pm 0.21$ & $1 \times 10^{-5}$ \\
& & 0.48 & $1.02 \pm 0.17$ & $1 \times 10^{-6}$
\end{tabular}

FRC: functional residual capacity (L); TLC: total lung capacity (L); VC: vital capacity (L); TL,CO: lung transfer factor for carbon monoxide $\left(\mathrm{mL} \cdot \mathrm{min}^{-1} \cdot \mathrm{mmHg}^{-1}\right) ; \mathrm{H}$ : height $(\mathrm{cm})$; TVI: thoracic volume index (L); PST: pubertal stage by Tanner scale. $\#$ : lung function/predicted lung function (mean $\pm \mathrm{SD})$.

females aged 13-18 yrs whose PST ranged T2-T4. All but three of the females had undergone menarche. Analysis of the distribution of the subjects within the Tanner rating scales shows that males and females in prepubertal or early pubertal stage (T1 and T2 in males and $\mathrm{T} 1$ in females) were lacking, and most females were investigated following menarche.
Although the mean ages of the males and females were comparable and the group of males slightly more mature, height, weight, TVI and pulmonary function test measurements in the males continued to increase with age, whereas those in the females did not. These data, although cross-sectional, suggest that, in the present group of males, lung and thoracic development 
Table 6. - Multiple regression equations for adolescent females

\begin{tabular}{lcccc}
\hline Dependent variable & Equation & Adjusted R $^{2}$ & Residual $^{\#}$ & p-value \\
\hline FRC & $0.0768 \mathrm{e}^{0.0203 \mathrm{H}}$ & 0.30 & $1.02 \pm 0.20$ & $1 \times 10^{-4}$ \\
& $0.10373 \mathrm{e}^{0.01768 \mathrm{H}} \mathrm{e}^{0.04546 \mathrm{PS} t}$ & 0.41 & $1.01 \pm 0.17$ & $1 \times 10^{-4}$ \\
TLC & $-7.6607+0.0752 \mathrm{H}$ & 0.46 & $1.00 \pm 0.12$ & $1 \times 10^{-7}$ \\
& $-8.306+0.0763 \mathrm{H}+0.0693 \mathrm{TVI}$ & 0.55 & $1.00 \pm 0.11$ & $1 \times 10^{-6}$ \\
VC & $-5.4044+0.0556 \mathrm{H}$ & 0.50 & $1.00 \pm 0.10$ & $1 \times 10^{-7}$ \\
& $-4.1863+0.0430 \mathrm{H}+0.1378 \mathrm{TVI}$ & 0.54 & $1.00 \pm 0.10$ & $1 \times 10^{-6}$ \\
TL,CO & $11.5869+3.643 \mathrm{PST}$ & 0.21 & $1.00 \pm 0.16$ & $1 \times 10^{-2}$ \\
\hline
\end{tabular}

FRC: functional residual capacity (L); TLC: total lung capacity (L); VC: vital capacity (L); TL,CO: lung transfer factor for carbon monoxide $\left(\mathrm{mL} \cdot \mathrm{min}^{-1} \cdot \mathrm{mmHg}^{-1}\right)$; $\mathrm{H}$ : height (in centimetres); PSt: pubertal stage by time since menarche (yrs); TVI: thoracic volume index (L); PST: pubertal stage by Tanner scale. \#: lung function/predicted lung function (mean \pm SD).

was still occurring, whereas it was almost complete in the females. This is in agreement with the data of LEBOwitz and SHERriLl [3] showing that, in males, lung and thoracic development is observed during and until the end of puberty. Conversely, in females, lung development occurs over a shorter period of time and earlier in the pubertal process. In addition, the present data show that, in females, lung development is almost complete after menarche.

Analysis of the variance of the pulmonary function test data showed that the variance of $T \mathrm{~L}, \mathrm{CO}$ in males and FRC in females increased with the mean, i.e. the scatter increased in proportion to the predicted value. This heteroscedasticity is frequently observed in the paediatric age range [16]. Logarithmic transformations stabilised the variance as anticipated. Conversely, the variance of all other pulmonary function test data did not increase with the mean. This can be explained by the fact that the present sample included a limited range of ages and heights.

In females, the anthropometric parameter best correlated with pulmonary volumes was height. In males, this was the TVI. In both sexes, PST was the anthropometric parameter that best correlated with $T \mathrm{~L}, \mathrm{CO}$, followed by height in males. Multiple regression equations were therefore determined, entering as independent variable height, TVI, pubertal stage for lung volumes, and height and PST for TL,CO.

Compared with the data of COOK and HAMANN [17], suggested for use in the age range 5-18 yrs for gas dilution methods [16], the present equation predicts comparable values for TLC in males and females but slightly lower FRC and RV.

Compared with the equations of regression of FRC, $\mathrm{VC}$ and TL,CO with height that have been defined previously in the present authors' laboratory in younger children using the same techniques [12, 18-20], a smooth transition from the equation of younger children to that of adolescents is observed for all lung volumes (FRC, VC and TLC) as a function of height in females and only for FRC in males. In males, the transition is less perfect for VC, TLC and TL,CO as a function of height as the slope increases during adolescence. This marked acceleration in the development of lung volumes, such as VC and TLC, during puberty in males compared to their linear increase from childhood to puberty in females can be related to differences in the development of muscle strength between the sexes. Indeed, muscle strength increases linearly with chronological age from early childhood to $\sim 13-14$ yrs in males, when there is a marked acceleration in strength development until age 20 yrs. In females, muscular strength improves linearly with age until $15 \mathrm{yrs}$, which is then followed by a tendency to level off [21]. Concerning TL,CO, a marked acceleration in the development of TL,CO during puberty is observed more strongly in males than in females and could be related to the adolescence growth spurt of the heart and lung, which become bigger not only in absolute terms but also in relation to body size, whereas a considerable increase in blood haemoglobin concentration provides greater capacity for carrying oxygen [22]. In females, as no correlation was observed between $T \mathrm{~L}, \mathrm{CO}$ and height, the prediction equations for the $T \mathrm{~L}, \mathrm{CO}$ of adolescents could not be compared to the children's one.

TVI and pubertal stage were included in the prediction equations in order to maximise the variance explained by the model $\left(\mathrm{R}_{a}^{2}\right)$. As a general rule, $\mathrm{R}_{a}^{2}$ were higher in males than in females. The efficiency of TVI and pubertal stage in increasing $\mathrm{R}_{a}^{2}$ depends on sex and the dependent variable studied (lung volumes or $T \mathrm{~L}, \mathrm{CO}$ ).

Considering the effect of sex on the prediction equations for lung volumes, as the females in the present study had probably completed most of their lung growth, factors supposed to explain lung growth and increase $\mathrm{R}_{a}^{2}$, such as pubertal stage or TVI, were less efficient [2] in that group. Conversely, $\mathrm{R}_{a}^{2}$ were higher in males even though early pubertal stages were not represented due to the fact that lung growth occurs later in puberty in males and the time lag between height and lung growth was still present.

In both sexes, the variable that best predicted $T \mathrm{~L}, \mathrm{CO}$ was PST, associated with height in males. The importance of using an index of maturity when describing the increase in $T \mathrm{~L}, \mathrm{CO}$ in males and females may, in part, be ascribed to the delayed development of cardiac function during the pubertal process compared to the development of lung volumes. Indeed, SEELY et al. [6] showed that sex difference in cardiac output develops late in the pubertal process, i.e. age 14 yrs in females and age 16 yrs in males.

In conclusion, the present study provides reference values for thoracic measurements, thoracic volume index, lung volumes (such as vital capacity, functional residual capacity and total lung capacity) and pulmonary diffusing capacity in a group of males aged 
13-20 yrs and a group of females aged 13-18 yrs. To date, no reference values of thoracic mensurations in adolescents have been published. The present data provide normal values for thoracic mensurations in adolescents for height and age that could be of help in quantifying the chest wall sequelae of treatments and the decrease in chest wall volume due to decrease in muscle strength in neuromuscular disease. In addition, this study has the advantage of providing reference values for lung volumes and diffusing capacity using equations which take into consideration, height, thoracic volume index and pubertal stage, an approach allowing for the variation in growth pattern between adolescents to be taken into account. Finally, the present data, although cross-sectional, confirm that, in males, lung and thoracic development is observed during and until the end of puberty. They also confirm that, in females, lung growth is of short duration and occurs early in the pubertal process and show that lung development is almost finished after menarche.

\section{References}

1. Wang X, Dockery DW, Wypij D, Fay ME, Ferris BG. Pulmonary function between 6 and 18 years of age. Pediatr Pulmonol 1993; 15: 75-88.

2. Sherrill DL, Camilli A, Lebowitz MD. On the temporal relationships between lung function and somatic growth. Am Rev Respir Dis 1989; 140: 638644.

3. Lebowitz MD, Sherrill DL. The assessment and interpretation of spirometry during the transition from childhood to adulthood. Pediatr Pulmonol 1995; 19: 143-149.

4. Underwood LE, Van Wyk JJ. Normal and aberrant growth. In: Wilson JD, Foster DW, eds. Williams Textbook of Endocrinology. 8th Edn. Philadelphia, PA, WB Saunders Company, 1992; pp. 1079-1138.

5. Shrader PC, Quanjer PhH, Olievier ICW. Respiratory muscle force and ventilatory function in adolescents. Eur Respir J 1988; 1: 368-375.

6. Seely JE, Guzman CA, Becklake MR. Heart and lung function at rest and during exercise in adolescence. J Appl Physiol 1974; 36: 34 40.

7. Dockery DW, Speizer FE, Ware JH, Ferris BG. Growth of pulmonary function between 6 and 18 years of age. Am Rev Respir Dis 1987; 187: 135.

8. Borsboom GJJM, van Pelt W, Quanjer PH.
Interindividual variation in pubertal growth patterns of ventilatory function, standing height, and weight. Am J Respir Crit Care Med 1996; 153: 1182-1186.

9. Tanner JM. Growth at Adolescence. 2nd edn. Oxford, Blackwell Scientific, 1962.

10. Howatt WF, DeMuth GR. Configuration of the chest. Paediatrics 1965; 35: 177-184.

11. Rosenthal $\mathrm{M}$, Bain $\mathrm{SH}$, Cramer $\mathrm{D}$, et al. Lung function in white children aged 4 to 19 years: I Spirometry. Thorax 1993; 48: 794-802.

12. Chaussain M, Denjean A, Lebeau C, De Lattre J, Badoual J. Lung transfer factor for $\mathrm{CO}$ at rest in normal children by a steady state method. Bull Eur Physiopathol Respir 1982; 18: 411-417.

13. Quanjer PhH, Tammeling GJ, Cotes JE, Pederson OF, Peslin R, Yernault JC. Lung volumes and forced ventilatory flows. Report Working Party "Standardization of Lung Function Tests", European Community for Steel and Coal. Official Statement of the European Respiratory Society. Eur Respir J 1993; 6: Suppl. 16, 5-40.

14. Armitage P, Berry G. Statistical Methods in Medical Research. 3rd edn. Oxford, Blackwell Science, 1994.

15. Chinn S, Rona RJ. Height and age adjustment for cross sectional studies of lung function in children aged 6-11 years. Thorax 1992; 47: 707-714.

16. Stocks J, Quanjer PhH. Reference values for residual volume, functional residual capacity and total lung capacity. ATS Workshop on Lung Volume Measurements. Official Statement of the European Respiratory Society. Eur Respir J 1995; 8: 492-506.

17. Cook CD, Hamann JF. Relation of lung volumes to height in healthy persons between the ages of 5 and 38 years. J Pediatr 1961; 59: 710-714.

18. Gaultier C, Boulé M, Allaire Y, Clément A, Girard F. Growth of lung volumes during the first three years of life. Bull Eur Physiopathol Respir 1979; 15: 1103-1116.

19. Taussig LM, Harris TR, Lebowitz MD. Lung function in infants and young children. Am Rev Respir Dis 1977; 116: 233-239.

20. Boulé M, Gaultier C, Girard F. Lung transfer for carbon monoxide during the first three years of life. Bull Eur Physiopathol Respir 1986; 22: 467-471.

21. Malina RM. Growth of muscle tissue and muscle mass. In: Falkner F, Tanner JM, eds. Human Growth. Volume 2. Postnatal Growth. London, Baillière Tindall, 1978; pp. 273-294.

22. Marshall WA. Puberty. In: Falkner F, Tanner JM, eds. Human Growth. Volume 2. Postnatal Growth. London, Baillière Tindall, 1978; pp. 141-181. 